\title{
Crowdsourcing Culture: Challenges to Change
}

\author{
Dora Constantinidis
}

\begin{abstract}
Cultural heritage is a perishable resource that is not renewable and is at constant risk of permanent loss. Galleries, libraries, archives and museums (GLAMs) have traditionally been regarded as the guardians and gatekeepers of a nation's culture and have taken on the role of "protecting" heritage. This traditional role can now be extended to incorporate the curation of digital cultural heritage, including that sourced by citizens (crowdsourced). By asking the public for their assistance to preserve their heritage, albeit by digital means, two objectives are achieved. One outcome is the creation and preservation of digital cultural heritage for future generations. Another significant outcome is that crowdsourcing provides a conduit for increased public engagement with heritage that is of significance and relevance to them. The current ability to crowdsource digital cultural heritage potentially challenges the role and status of GLAMs as primary caretakers of heritage. Since the public can play a greater role in preserving their heritage, authoritative control will need to be reconsidered and adapted to align with heritage that has been deemed important by people. Irrespective of these challenges the opportunity to digitally preserve heritage should take precedence, especially in high risk countries facing conflict and socio-political unrest. This chapter will highlight some of the challenges of engaging people with crowdsourcing cultural heritage and the requirement of designing appropriate engagement strategies. The need for crowdsourcing Afghan cultural heritage will be considered given that it is currently facing many threats to its preservation for future generations.
\end{abstract}

D. Constantinidis $(\bowtie)$

University of Melbourne and Monash University, Melbourne, VIC, Australia

e-mail: dorac@unimelb.edu.au; dora.constantinidis@monash.edu 


\section{Introduction}

Digital crowdsourcing is generating increased research output and applications. Digital devices provide the capability to better engage people's interest and commitment to collectively share their efforts in generating data and information to benefit the wider community. Most noteworthy are citizen scientists who can contribute by digitally monitoring and recording the natural world ranging from flora and fauna, to astronomical phenomena, and of relevance to this chapter, by digitising cultural heritage. Crowdsourcing digital cultural heritage is proposed as an enabler in efforts to rescue and save heritage under threat. The chapter commences with an overview, in Sect. 2, of the significant role cultural heritage plays in society and the need for its preservation in light of the threats it often faces. With a focus on Afghan cultural heritage, a range of hazards are prioritised to create a stronger awareness of the need to deploy suggested strategies based on digital platforms that can help preserve heritage not only in Afghanistan but worldwide. Section 3 then highlights in more detail some potential digital preservation strategies for the protection of cultural heritage with an emphasis on digital crowdsourcing. The need to identify change and engage agents is pivotal to any crowdsourcing project and is discussed in Sect. 4. This section provides insights into the importance of change agents and how crowdsourcing projects can improve their chances of success if appropriate change agents are in place. An example of a change agent as an engage agent is proposed for the case of Afghan cultural heritage as a potential driver to help preserve that nation's culture. A significant means of heritage preservation could be instigated by education campaigns inspired by a change agent's message to people to provide, for example, digital photographs on coordinated digital platforms. Section 5 then goes on to present how crowdsourcing can transform both the protection and dissemination of cultural heritage including how its digitisation can also lead to its virtual restoration. Finally in Sect. 6 some future directions for crowdsourcing digital cultural heritage are presented.

\section{Cultural Heritage: Significance and Threats}

Family heirlooms facilitate a connection to our personal past, and can contribute to shaping and affirming our individual identities (Belk 1990). For connection to a public past, cultural heritage positions this within a more collective context. Cultural heritage can be considered to be the national heirlooms created by previous generations, typically consisting of physical constructs that include buildings and crafted landscapes. Traditionally galleries, libraries, archives and museums (GLAMs) are the collective "homes" that store and display national heirlooms. Significant or rather "monumental" tangible culture is predominantly curated by museums in order to showcase a nation's heritage (McIntosh and Prentice 1999). What this chapter will present are strategies to digitally crowdsource tangible heritage beyond the confines and constraints of GLAMs. The proposed strategies 
can be extended to intangible aspects of cultural heritage such as folklore, music, dances and stories, which can also be captured and disseminated by digital means.

Museums usually promote the collective identity of a nation to its citizens and the rest of the world by sharing tangible, cultural heritage which is status-oriented and affect-generating (Assmann and Czaplicka 1995). Sharing cultural heritage can also potentially help bridge differences amongst diverse groups of people within one nation (Ashworth et al 2007). Preserving and sharing, for example, Afghan cultural heritage can play a very important role in peace building (Dupree 2002). An inscribed plaque and banner at the Kabul museum provides a very emotional reminder of the great impact cultural heritage can have on the identity of its people, all 30 million or so in Afghanistan. The current director of the Kabul museum quite emphatically reinforces what has been inscribed on the plaque: "A nation stays alive when its culture stays alive" (Massoudi et al. 2015). Beyond the sentimental and emotional value of cultural heritage for its citizens (Silberman and Purser 2012), it can also provide a means of regenerating the fundamental values of a broken nation and restore some normality to people and their communities. But unfortunately, this most valuable and irreplaceable resource is being exploited with quite the opposite effect. Cultural heritage, both tangible and intangible, faces an onslaught of threats worldwide (Blake 2000) and especially in Afghanistan.

Archaeologists are often associated with uncovering cultural heritage as the physical artefacts and remains of buildings at archaeological sites. Their work is especially pertinent for archaeological salvage operations especially those in war-torn areas such as Afghanistan. Unfortunately remnants of past cultures are often lost forever due to numerous significant threats, the impact level of which can be graded relative to the context they appear in. An attempt to grade threats to cultural heritage in Afghanistan is presented in Fig. 1 below. Cultural heritage is mainly threatened by looting, direct conflict, mining and construction developments. Given all these threats that often lead to a permanent loss of heritage, at the very least, digitally recording tangible heritage wherever possible can help preserve the past. Preservation and access to the past is considered to be a basic human right (Francioni 2008; Silverman and Ruggles 2007; Iacovino 2015).

Physical preservation of threatened heritage is paramount and preferable; however crowdsourcing cultural heritage with mobile devices in whatever mode (Owens 2013; Oomen et al. 2011) should become another avenue for its preservation, especially under dire circumstances. Despite the complexity of challenges that exist in extreme situations, unless there is a pressing humanitarian crisis provoked by war, motivating and generating the interest of local populations to preserve their own cultural heritage with mobile phone cameras may be a viable solution (Alam et al. 2012). By analysing local social drivers, including the most popular means of public communication, and taking ethical approaches in the use of new technology to protect peoples' privacy and security, crowdsourcing can lead to an effective strategy to digitise cultural heritage that people come to engage with and care about (Ridge 2013; Tait et al 2013). Given that most mobile phones are now equipped with Global Positioning Systems (GPS), the location of any photographed heritage can automatically be captured as well (Han et al. 2014b). With the creation and 


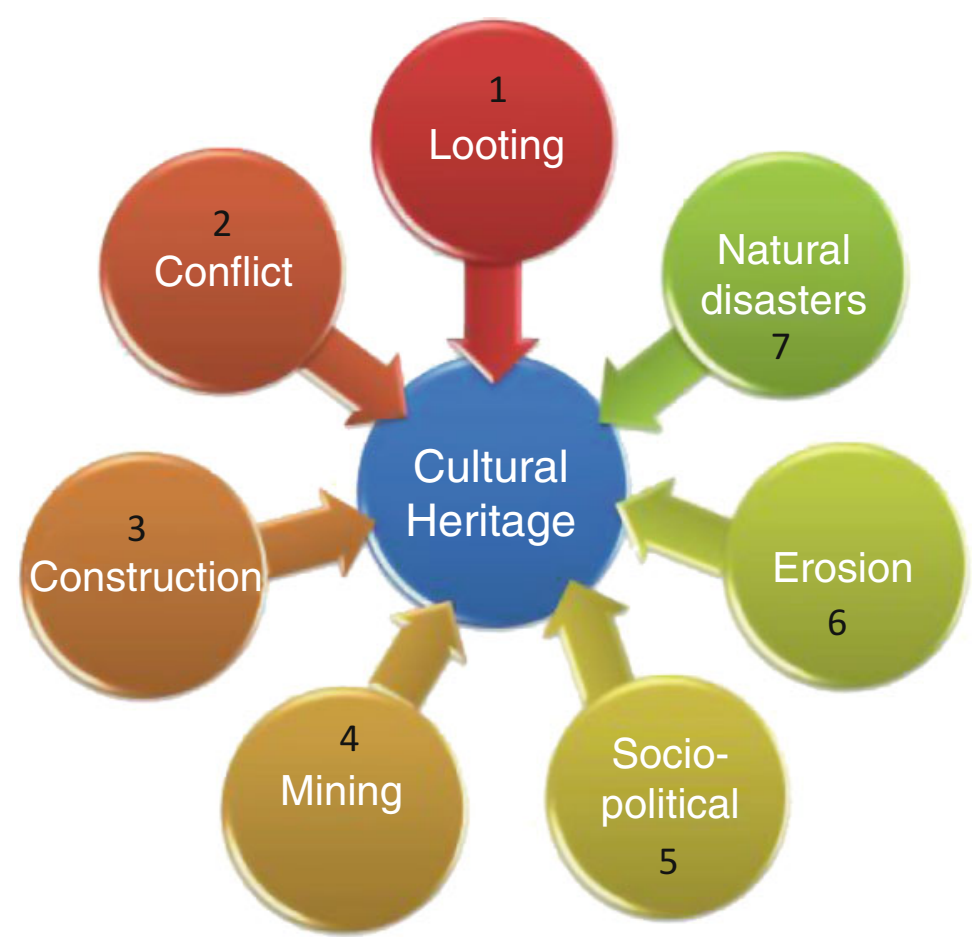

Fig. 1 A proposed gradation of threats to cultural heritage in Afghanistan

availability of a Geographical Information System (GIS) database that can store crowdsourced geo-tagged photos, an archive of digital cultural heritage could then be accessed within a cyber-context by people who took the photos as well as be preserved for future generations for both viewing and analysis, which can include all the spatial attributes as well.

Amidst challenging circumstances in Afghanistan, archaeological salvage operations continue to rescue heritage especially from looters (Benard 2012; Brodie et al 2006). Looting is an age old problem, where cultural heritage such as antiquities are sold for sheer profit. Archaeologists in Afghanistan have reported seeing antiquities being sold in shops in Kabul. Heritage artefacts are even sold in the virtual marketplaces of the internet (Campbell 2013). Despite determined efforts to prevent looting, there is an ever increasing worldwide rise in the loss of heritage by this threat. It will take very targeted and sustained multinational campaigns to prevent the selling and buying of tangible cultural heritage by everyone involved (Brodie et al 2001). For now, the race is on between the archaeologists and the looters. Unfortunately the looters are apparently winning at the moment because unless archaeologists can get to sites before looters do, cultural heritage is displaced and any chance for a better understanding of the past is lost forever. 
Looting is unfortunately aggravated during times of conflict, with the added burden that archaeological sites are often destroyed because of their proximity to strategic military positions. The site at Mes Aynak is an example of work by Afghan archaeologists who rushed to save what they could when they became aware that it was being looted (Benard 2012). However in this case added to that, is the threat to the site by nearby copper mining (Bloch 2015). Mining can perhaps be placed on the same level of threat as construction in Afghanistan. With an estimated 1 trillion dollars of lithium reserves alone, and billions of dollars of other precious minerals, such as copper, this threat will significantly increase (Risen 2010). Ironically, when national security can be guaranteed it is more than likely that mining companies will expand (Wilson 2010). Hence the threat mining poses to the destruction of cultural heritage is expected to increase and will significantly impact efforts to rescue the cultural heritage of Afghanistan.

Construction and development is another major threat, especially with the expansion of new infrastructure such as roads. This is a real issue in Afghanistan, because the traditional silk route followed the most convenient path through a landscape that has not changed much in over 2000 years. In the process of improving the existing road network, any sites that are located on or near the silk route will come under serious threat. Another serious threat that is also caused by people arises from extreme socio-political outlooks. A preeminent example of this threat having already occurred in Afghanistan is the destruction of the Buddha statues at Bamiyan (Flood 2002). Finally, erosion and natural disasters, such as earthquakes, are always potential threats however in most cases there is very little control over these. This aggregate of threats to cultural heritage worldwide, and especially in Afghanistan, unfortunately permeates all of cultural heritage both tangible and intangible. Any loss of cultural heritage leads to people being further disconnected with their past which eventually will result in impoverishing theirs and future generations' identities (Silberman and Purser 2012). By exploring new digital avenues for capturing and sharing images of culture via mobile devices and online websites, these can, at the very least, 'virtually' preserve and provide some connection to the past, albeit in a digital format (D'Alba et al 2015; Loh 2010). This provides a 'shifting affordance' strategy from the traditional physical presentation of culture in bounded static places (such as museums and galleries) to fluid, location-free and on-demand access to digital cultural heritage, which regrettably in some cases may no longer physically exist.

\section{Developing Digital Preservation Strategies for the Protection of Cultural Heritage}

Multiple digital enablers are playing a significant role in rescuing, gathering, and provisioning pervasive access to cultural heritage within a cyber-context (Terras 2015; Tait et al 2013). Digital preservation strategies involve an ongoing process of recording, storing, accessing and disseminating digitised cultural heritage products that can then inspire further cycles of this process. Figure 2 represents a high level 
Fig. 2 The lifecycle of digitised cultural heritage

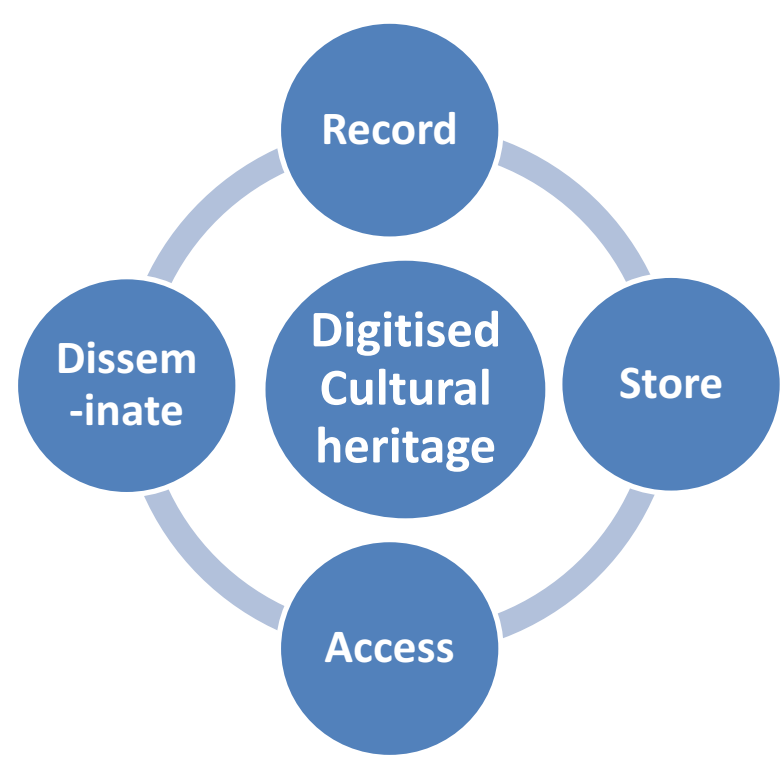

process of digitising either tangible or intangible heritage which facilitates a digital avenue to preserve threatened cultural heritage for current and more importantly future generations (Chowdhury and Ruthven 2015).

Any part of the process of preserving cultural heritage by digital means can impact numerous efforts to combat many of the threats it faces. For instance the threat that exists due to looting cultural heritage could potentially be counteracted with targeted online social media campaigns incorporating a dissemination of digital cultural heritage images and information. This can even lead to naming and shaming people who buy looted artefacts thus effectively drying up the market for illicit antiquities. On the other hand, with the availability of online digital access, GLAMs are increasingly engaging in participatory crowdsourced contributions that can also include informed annotation for their digitised cultural heritage collections (Dijkshoorn et al 2012; Tait et al 2013). Digitised images of cultural heritage can be used to create virtual reconstructions of objects and entire sites (Gruen et al 2014) that in most cases can be viewed online by anyone in the world with access to the internet. This worldwide dissemination of digital cultural heritage can lead to increased interest and ultimately improved preservation of cultural heritage. As for the transition to the mobile era, archaeologists are now afforded the use of mobile phones to gather data in the field far more conveniently than ever before.

Because artefacts and ancient structures are found in specific locations at a site, a Geographical Information System (GIS) is the most appropriate means to store and then view heritage data on maps. Spatially referenced objects comprised of the artefacts and buildings found at a site need to be recorded within the context of their immediate surroundings so that any spatial relationships and patterns are later 
investigated for clues about how people lived in the past. For archaeologists the most time-consuming task is to carefully record all these spatially referenced data and store them in a format that can then be easily accessed for later analyses. This is where computer technology such as GIS can come to the rescue by helping to create digital records that make it easier for geo-locational and spatially bound analyses to be conducted. There are apps or programs that archaeologists can adapt and use on their mobile phones to record and analyse spatial data even in real time. A leading GIS company has already developed an app available on mobile phones to record spatially referenced objects (ESRI 2015).

There are also an increasing number of freely available open-source apps such as the Federated Archaeological Information Management System (FAIMS 2014). The FAIMS app is presented as having been specifically designed for archaeologists and is free to use (Pearce 2013), benefitting many cash-strapped archaeological projects. In the news release Pearce (2013) states that this app can help the way archaeologists capture and record data: "The app allows the recording of text, location, imagery, and audio data on Android devices. The system will also allow data captured by other devices, images from SLR cameras, or [scanned] drawings done by hand to be linked to the records". Given such efficient digitisation of artefacts, the faster archaeologists can gather data with tools such as these, the better chance there is of getting to other sites and saving cultural heritage before looters and other threats destroy it. This is especially pertinent during times of war and conflict, because with conflict comes the added threat of losing cultural heritage to accidental digging as well. Soldiers often unknowingly end up digging artefacts, displacing their all-important spatial contexts, and all the valuable information that goes with that. So apart from being destroyed by rocket fire, cultural heritage is also threatened by soldiers just setting up camp and especially in Afghanistan with such a wealth of artefacts found almost everywhere one digs.

Even though conflict poses so many threats to cultural heritage, archaeology is not usually a priority, for obvious reasons. This was definitely true during the First and Second World Wars, when many major archaeological excavations were put on hold and regrettably a large degree of cultural heritage was destroyed. The destruction of so much cultural heritage during times of conflict was officially recognised by UNESCO after the Second World War and stringent policies were implemented to minimise and mitigate threats to a greater extent than those already established by the Hague Convention in 1899 (Hague 1899). The 1954 Hague Convention states:

\footnotetext{
The Convention for the Protection of Cultural Property in the Event of Armed Conflict adopted at The Hague (Netherlands) in 1954, as a consequence to the massive destruction of the cultural heritage in the Second World War, is the first international treaty of a worldwide vocation dedicated exclusively to the protection of cultural heritage in the event of armed conflict... The Convention was adopted together with a Protocol in order to prevent the export of cultural property from occupied territory, requiring the return of such property to the territory of the State from which it was removed (UNESCO 1954).
}

After the Second World War, these initiatives by UNESCO led to establishing the 1954 Hague Convention that aims to implement policies to protect cultural heritage during times of conflict. UNESCO clearly recognising the pivotal 
importance of cultural heritage by stating that: "cultural heritage reflects the life of the people, its history, and its identity. Its preservation helps to rebuild broken communities, re-establish their identities, and link their past with their present and future."(UNESCO 1954). The 1954 Hague Convention was subsequently modified to align with more recent events, as is illustrated by the second protocol that was ratified in 1999, which states:

The destruction of cultural property in the course of the conflicts that took place at the end of the 1980s and the beginning of the 1990s, highlighted the necessity for a number of improvements to be addressed in the implementation of the Hague Convention. A review of the Convention was initiated in 1991, resulting in the adoption of a Second Protocol to the Hague Convention in March 1999 (UNESCO 1999).

One of the outcomes of this resulted in increased campaigns for cultural heritage training of military personnel to make them more aware and more sensitive to the issues concerning the protection of cultural heritage during war. The document suggests:

Training for the military with particular reference to Article 7 of the 1954 Convention provides for the obligation to introduce in time of peace into the military regulations or instructions such provisions as may ensure observance of the Convention to establish, within armed forces, services which secure respect for cultural property and to co-operate with the civilian authorities responsible for safeguarding it (UNESCO 1999).

It is noteworthy that UNESCO places emphasis on cooperation with civilian authorities responsible for safeguarding cultural property. This implies that GLAMs are the responsible civilian authorities to ensure the preservation of cultural heritage. However given the availability of digital enablers such as mobile phones, crowdsourcing such efforts beyond GLAMs are now plausible and UNESCO may soon incorporate the importance of crowdsourcing culture by "non-authoritative", local people into its policies as well.

Currently any UNESCO abiding military force, by necessity, will provide at the very least, pocket guides made available for troops to read about the important role they can play in safeguarding cultural heritage in conflict zones. Within the last two decades these pocket guides have also been transposed to online resources, such as the US Department of Defence: Cultural Property Training Resource website, with reference in this case to troops deployed to Afghanistan (DoD 2013). This online resource is transparent and can also be accessed by civilians who can "take the test" to assess their knowledge on how to protect cultural heritage in conflict zones. This website is yet another example of a digital preservation strategy as dissemination of information, with examples of digitised cultural heritage made available online for education and training of military personnel about how to protect cultural heritage during times of conflict.

Unfortunately despite all these initiatives and policies, there are still destructive forces at work that undermine efforts to preserve cultural heritage, especially in times of insurgency. Often it seems that the representative blue symbol placed at cultural heritage sites around the world, is just that: another symbol. Despite all the efforts of UNESCO, and good intentions internationally, the Buddhist statues at 
Bamiyan were still blown up, and looters continue to loot. However there is growing recognition that power to overturn all this destruction can be sourced from change, a change in people's attitudes towards cultural heritage through education. If people's attitudes do change, then there is real hope. Digital technology, like never before, can be a very influential driver for such change (Han et al. 2014a). Education can come in many formats, and internet websites can provide a powerful catalyst for this.

The Association for the Protection of Afghan Archaeology (APAA), which was established by the former Director of Afghan Archaeology, Dr. Tarzi, has coordinated the creation of the APAA website. This website provides a very rich resource of information freely available on the internet. The association publicly acknowledges the need for change and is even petitioning for it online. The Change.org online petitioning website included as a link on the APAA website is there to engage and motivate people to provide a sustained effort to help preserve, in this case, the cultural heritage of Afghanistan. This is another example of crowdsourcing but in this case as online support for the recognition of the important role cultural heritage can play in nation building. Current research into gamification (Flanagan et al 2013; Paraschakis and Friberger 2014) and other strategies to motivate people to participate with crowdsourcing in a cyber-context (Ridge 2013), may possibly lead to an increased understanding of what motivates and even de-motivates people to contribute to crowdsourced projects (Alam and Campbell 2012). This research may be pivotal in reducing the current threats that cultural heritage faces by providing key strategies to motivating especially local people to digitally crowdsource images of their cultural heritage. A solution for saving whatever remains of heritage for future generations may be provisioned as crowdsourced projects become more effective, with the help of well-established virtual online communities (Gregory 2014). So the opportunity for protecting cultural heritage, and especially that which is threatened under extreme circumstances, may ultimately come to rely more so on well executed crowdsourcing initiatives.

\section{Crowdsourcing Cultural Heritage Motivators: CHANGE $=$ ENGAGE Agents}

Crowdsourcing projects could benefit from key influential people called change agents, especially in regions under the threat of social and political instability. These actors can instigate change (Caldwell 2003) and be pivotal in engaging others to act for the common good, which in this context would be to preserve cultural heritage in Afghanistan. In the case of Afghan cultural heritage, the most appropriate change agent is the current Director of the Kabul Museum, Omara Khan Massoudi, who, despite great threats to his personal safety, managed to coordinate the rescue of the "Afghanistan treasures" which are currently touring the world (Afghanistan 2015). Thanks to Massoudi, and staff at the Kabul Museum, these treasures were not lost forever and, because of him, other cultural heritage may also 
be rescued from destruction. Massoudi could definitely play a significant role as a change agent to inspire and engage other people, especially in the education of children. Education is fundamental in facilitating change to which children are more likely to respond to. With whatever means for delivering education, change for the better has an excellent chance of succeeding. We all know from personal experience that what we learn as children, we never forget, and it lives with us for all our days, so the hope for any change will ultimately be by educating children in Afghanistan. With only an estimated $10 \%$ of people having access to the internet, for now the most effective educational campaigns will be in schools and by radio. In Afghanistan, radio communication has already been exploited as an effective communication medium for promoting Afghan nationhood (Dupree 2002). Radio programs can be developed specifically to educate people about the importance of saving their cultural heritage since this is the most appropriate means for effectively communicating this message at the moment.

However given that mobile phone usage is rapidly increasing in Afghanistan, educational campaigns on protecting cultural heritage could also be delivered as online content and even as apps. When education on cultural heritage is effectively coordinated in Afghanistan, then mobile phones can also help protect and preserve it. Firstly by educating people on the importance of protecting their cultural heritage and then in turn, having people go out and photograph it with their mobile phones, hence preserving it, albeit in a digital format. However communication technology and devices on their own are of no use if people do not see the point. People do need to be inspired: the Book of Proverbs (29:18) states that "Where there is no vision, the people perish". This is where increased access to virtual images of cultural heritage could inspire people to participate in a more concerted effort to rescue their heritage. People in Afghanistan could upload photos of their cultural heritage online to a dedicated website for the entire world to see, hence effectively providing them with a deeper sense of cultural heritage ownership. Crowdsourcing, as the name suggests, relies on people power: it is within the hands of the people to make a difference and, in this case, to cultural heritage.

Victor Sarianidi, who had excavated the Tillya Tepe Bactrian treasures which are now associated with rediscovery of the "Treasures of Afghanistan", believing that they had been lost forever, said in great despair, "Now all that we have left are photos." That was true, for just over 20 years. What remained of the treasures were only their images, reflected by the eyes of the photographer, and it was fortunate that Sarianidi had taken many photos. In this case, it was even more fortunate that the physical manifestation of the treasures had been spared, thanks to the efforts of Massoudi and a select number of staff at the Kabul Museum (Sarianidi 2015). Photos, of course, can never replace cultural heritage, but considering all the threats it faces, it is better to have photos than have nothing at all. Increasingly museums have embarked on crowdsourcing activities in many formats, one of which is to ask visitors to share their impressions of the exhibitions by uploading their photos, as for example to the official Melbourne Museum website (2015). This is just one case of co-participatory crowdsourcing (Ridge 2013; Owens 2013). With digital cameras converged with mobile phones, creation and access to photographed 
images has been changed forever. Photos are no longer trapped in treasured family photo albums, photos are free. They can now be shared literally instantaneously all around the world.

Apart from dedicated websites where people can share photos for a specific museum context, there are many other online avenues to share photos. Crowdsourced photos in relation to local cultural heritage instigated by individuals on Facebook are gathering momentum (Gregory 2014). Another digital outlet for individuals is the Flickr site, where special interest groups can also be created, such as the one that the Melbourne Museum (2015) has generated and is using to power its own public crowdsourced photo album. Another place where photos can be shared is on Google Maps/Earth. Google Maps allows people to post photos on any point on their maps. Fortunately, photos sent to Google Maps are vetted to make sure that they are not going to offend anyone, a policy any publicly interfaced crowdsourcing effort should seriously consider. People are already posting photos relating to Afghanistan onto Google Maps. This collective, worldwide map-based photo album is being created at a phenomenal rate with an assortment of photos. There are for example even photos posted of camels out in the Afghan desert just north of Kabul, but of more relevance to consider are the photos of cultural heritage relating to Afghanistan.

The already posted photos of cultural heritage are very promising for any future official and authoritative coordinated effort to preserve Afghan cultural heritage by crowdsourcing strategies. Some current examples of Afghan cultural heritage posted to Google Maps are photos of the Buddhist statue niches cut into the rocky cliffs at Bamiyan. Even more fortunate are the photos that have been posted of the statues before they were blown up. Elios Amati posted one of these photos onto Panoramio (2013), a photo sharing platform which has now been incorporated and owned by Google Maps. Hopefully, more people will be inspired to follow suit and post more cultural heritage photos. With strategically elected change - engage agents promoting such campaigns even more images of heritage, especially that which has already been lost and destroyed, could be sourced by crowdsourcing.

Photos on Google Maps/Earth can also be annotated by others by tagging them online and if needed even correcting the location on the map where the photo was attached to. This reflects key strategies undertaken by a number of crowdsourced projects such as the Australian Newspapers Digitisation program that seeks public goodwill to correct scanned newspaper articles (Alam and Campbell 2012). In the case of photos posted to Google Maps/Earth, since people do not always click on the right location allowing this ability for the crowd to make corrections is an invaluable feature. However now that mobile phones have GPS, any photos can automatically be geotagged, with the earth's coordinates and even altitude embedded into them, thus reducing the need for people to correct locations. Given that photos on Google Maps/Earth are geotagged, later analysis of the distribution and extent of cultural heritage can also be better investigated, however taking into consideration that GPS, for the moment, does not accurately capture the distance from where the photo was taken. 
Google Earth incorporates additional GIS functionality that is not offered by Google Maps. Since Google Earth provides extra layers of geographical information about the surrounding environment this feature can be used to analyse the context in which crowdsourced photos were taken to provide for a better understanding of their overall location. Other features these photos have are tags and user generated text, and people can even elect to link Wikipedia entries to their photos. Despite the current challenges in managing (Chowdhury 2015a, b) and accessing all these free-style tags or folksonomies, the information people provide is widely recognised as a means for generating greater engagement in crowdsourcing efforts (Ridge 2013; Han et al. 2014a).

It is encouraging to see the increasing numbers of cultural heritage photos making an appearance on both Google Maps and Earth, especially for Afghanistan. As more photos are posted, eventually a timeline of cultural heritage can even be created. For example, when the Darul Aman Palace [translated as "abode of peace"] is finally restored to its former glory in Kabul, the archived photos of what it appeared as in its ruined state can serve as a stark reminder of a time when there was no peace. Another significant outcome when such crowdsourced images are carefully archived and community considerations taken into account, is the access that future generations will have to these photos (Iacovino 2015). With all these images on Google Maps/Earth, we will eventually be able to view changes in cultural heritage over time in order to reflect on the impact society has had on its cultural heritage and vice versa.

With appropriate change-engage agents in place, such as Massoudi in Afghanistan, people can be encouraged to post cultural heritage photos to Google Maps/Earth. As more significant numbers of people in Afghanistan are afforded the opportunity to participate in a digital preservation of their culture, a coordinated and specifically well-designed mobile app for local populations could dominate efforts to rescue heritage that is of significance to them (Chowdhury 2015a, b). Digital crowdsourcing facilitates an open creation and access to digital images of heritage by the public and for public consumption. In Afghanistan, people using mobile phones could take and then upload photos of cultural heritage to a specially created website, powered by a GIS database. The major mobile phone providers in Afghanistan could be enlisted to provide incentives for people to engage in such a crowdsourced project, whether it is giving them extra minutes of talk for every heritage photo they upload (for free) or whatever other means of motivation is deemed appropriate.

A dedicated website showcasing local people's photos could provide a strong impetus to change attitudes towards cultural heritage for the better. Mobile phones and crowdsourcing go hand-in-hand (Han et al. 2014b). The power of crowdsourcing is only as strong as the motivations and drive people have for collaborating, people drawing together to make a difference. There's real hope to protect and preserve cultural heritage in Afghanistan, not only in the cyber world, but in the real world as well. Despite all the challenges that Afghan people are currently facing, there is great potential for collaborative crowdsourced projects because the Afghan people already recognize the power of crowdsourcing: it is 
reflected in one of their famous proverbs which states that "Many drops make a river."

\section{Crowdsourcing Transformations: Cultural Heritage, Digital Protection and Restoration}

Concerted crowdsourcing campaigns have the potential to transform both cultural heritage protection and digital cultural heritage restoration. Apart from viewing photos of cultural heritage that both visitors and local Afghan people upload to either Google Maps/Earth, or a dedicated (GIS) website when it is established, these photos can also be used to digitally reconstruct destroyed heritage. The digital reconstruction of lost heritage could also be undertaken by crowdsourcing efforts as well. An example of this type of crowdsourcing project that has been implemented and is currently under construction is the Mosul Project. Project Mosul (2015) is an initiative led by researchers at ITN-DCH (2014). This crowdsourced driven project has been instigated to mitigate the destruction of cultural heritage by Daesh (IS). It uses crowdsourced imagery provided primarily by tourists who had previously visited these heritage threatened areas to reconstruct that which has now been destroyed. Photos are fundamental to this project since any that were taken of heritage that is now destroyed can be used to recreate virtual images of this. People who have taken photos of sites and artefacts are being encouraged to submit their photographs and these are then logged and digitised by volunteers as part of this crowdsourcing effort. It has been reported that the project has received more than 700 photos so far, including 543 showing artefacts from Mosul (Webb 2015). Currently an online "gallery" showcases fifteen 3D reconstructions, completed by nine volunteers (Project Mosul 2015). These reconstructions are important because while, "[t]hese models don't have the same scientific value as if we were able to do this with calibrated cameras, laser scans, etc. But the 3D models still have the value of the visualization-being able to see what the artefact was like." (Webb 2015). Despite the debate about the effectiveness of virtual museums (D'Alba et al 2015) and virtual reconstructions of heritage (Garau and Ilardi 2014), in the case of Iraqi and Syrian heritage, going virtual is the only option for making a connection to cultural heritage that has already been sadly destroyed.

Crowdsourced heritage photos, apart from offering the ability to digitally restore destroyed heritage, can also be incorporated into a dedicated online GIS database. Such online access could be made available for the purposes of recording cultural heritage directly onto digital maps by local people for example in Afghanistan. People, if they choose, can then have access to spatially referenced records that contain both text and images which are retrieved directly on maps. Any digitally reconstructed heritage could also be incorporated on such maps depicting where these heritage objects belong to spatially. Cultural heritage in a map-based context can also be tagged to allow for easier searching and discovery in a cyber-world. Three main levels of information delivery as depicted in Fig. 3 could not only give 


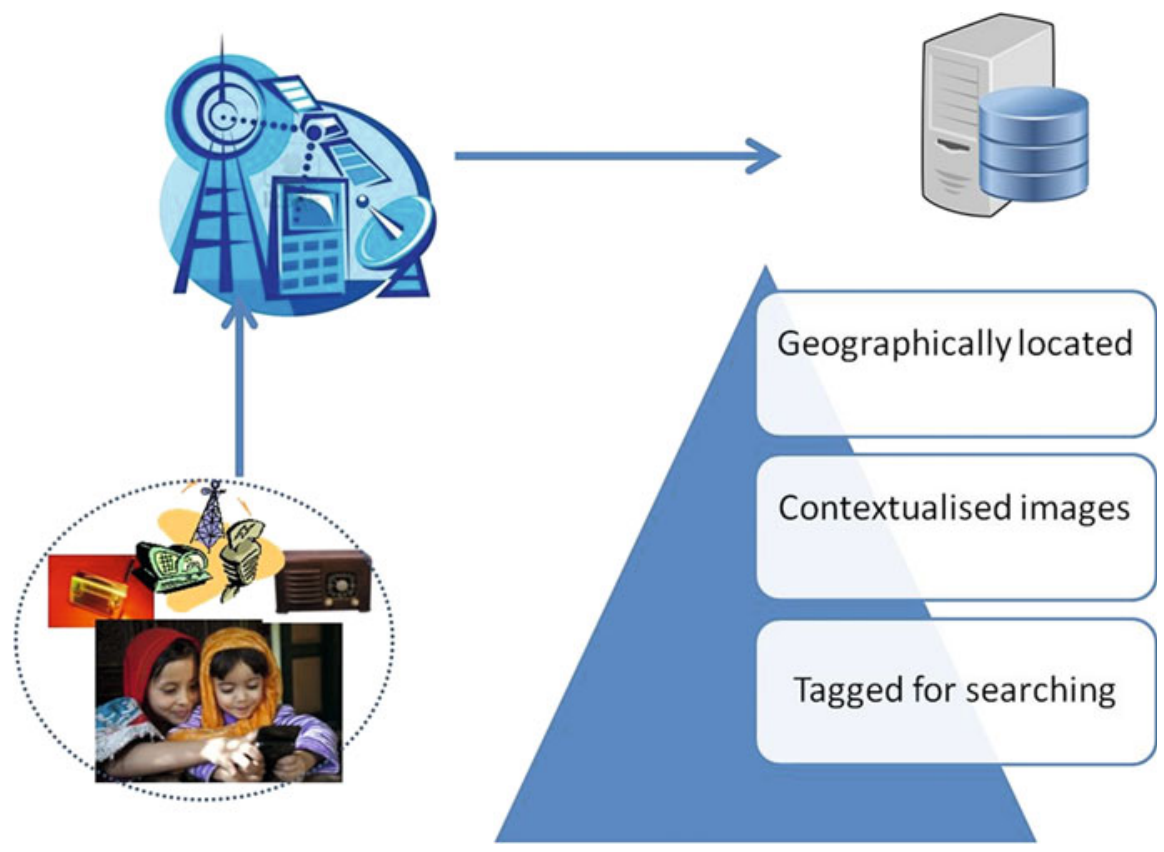

Fig. 3 Digitising spatial cultural heritage: Levels of digital information provision

"authorities" but local people as well the ability to geo-locate heritage and view this within its spatial context, thus providing a more holistic view of cultural heritage.

Access to a dedicated heritage GIS database from crowdsourced images would allow for map-based images of cultural heritage. These spatially referenced images could then also be used to curate a virtual spatial museum (Owens 2013). Digital curation strategies can only be developed given more insights about all the dimensions of digitised cultural heritage collections (Terras 2015). Given appropriately developed digital curation policies and outcomes, even physical museums such as the Kabul Museum could incorporate into their physical catalogues virtual images of cultural heritage. Ultimately the endowment of heritage via crowdsourcing, and the subsequent access to publicly sourced cultural heritage images via a mobile app or online website will allow for more personalised choices of heritage engagement. Once ethical and legal issues of privacy and IP are clearly established, initiating digital heritage exhibitions for education or entertainment can potentially be better informed within the context of being able to analyse public creation and consumption of heritage with the availability of digital analytics. This may then allow traditional GLAM institutions to design more user focused cultural exhibitions that better align with public choices (Chowdhury 2015a, b).

Furthermore in Afghanistan, the Archaeology Police could also benefit in their duties to better monitor heritage protection by accessing spatially referenced digital heritage images to flag any new heritage appearing at different locations on a map. 


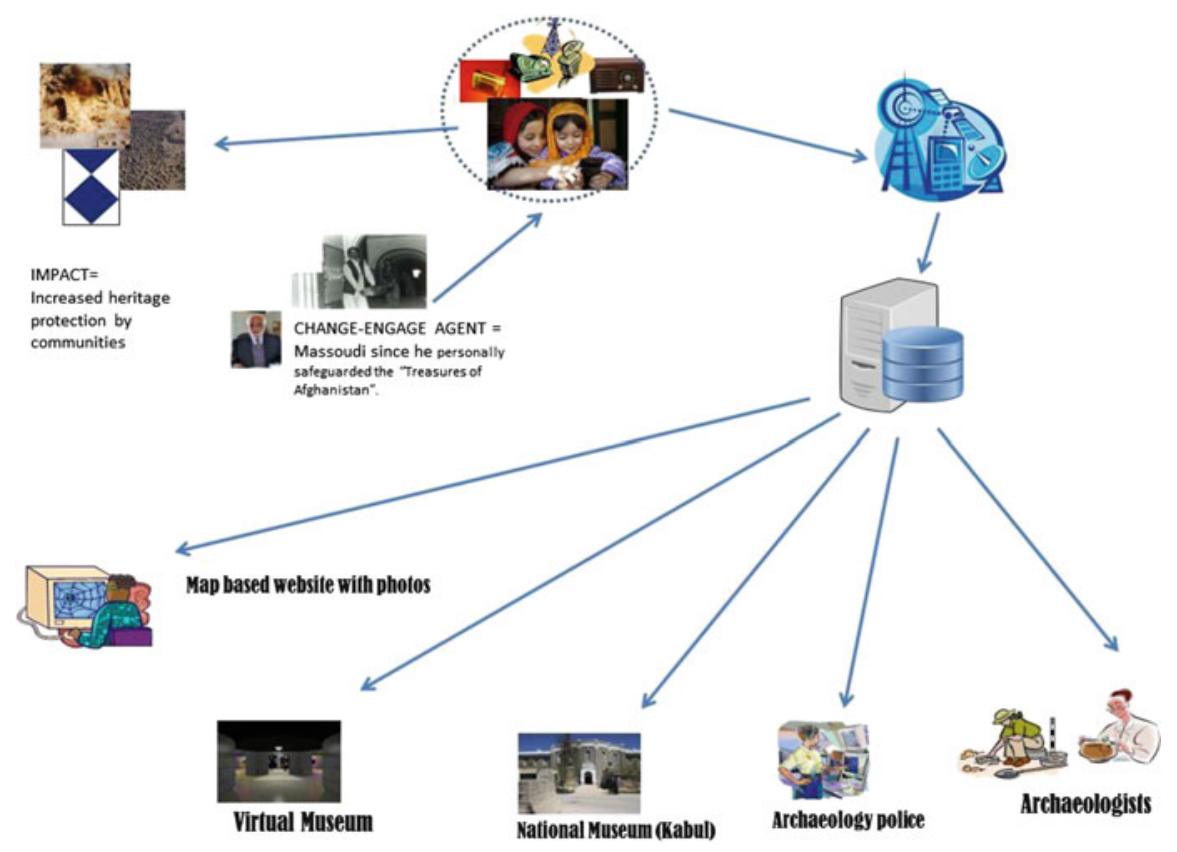

Fig. 4 Potential impact of digital protection strategy for cultural heritage in Afghanistan

Additionally archaeologists could also access spatially referenced images to help make better links to establishing spatial heritage patterns in the past. Therefore from crowdsourced photos and information, the potential output and impact to local communities and 'authorities' is significant. Hence designing and implementing appropriate crowdsourced projects is paramount. A proposed framework for implementing a crowdsourced project for the protection of Afghan cultural heritage is presented in Fig. 4. The integration of key change agents, such as Massoudi, to instigate targeted educational campaigns can possibly better engage people with their heritage inspiring them to participate in recording it. The consequence of this is a number of significant outcomes and impacts, discussed above and depicted in Fig. 4. These outcomes are likely to lead to an improved preservation of actual heritage and dissemination of digital heritage that can benefit both individuals and institutions such as GLAMs.

\section{$6 \quad$ Future Directions for Crowdsourcing Culture}

Having considered crowdsourcing for heritage under threat within the context of Afghanistan a number of observations for future research can be presented for cultural heritage that is not only threatened under extreme circumstances but is also threatened by a changing digital landscape. By facilitating a more proactive role in creating and accessing heritage that people make available, crowdsourced digital 
heritage collections can then challenge the domain and standards heritage professionals may be abiding by (Oosterman et al 2014). Digital curation policies for publicly sourced images of culture should also be considered in light of the more open access that crowdsourced projects promote. With the increasing availability of mobile devices that are GPS enabled, developing apps that can allow heritage images to be geo-located on digital maps and be made available to the public online and directly to their mobile devices also opens up new opportunities for traditional institutions to expand their horizons. Who, what and where heritage has been digitally captured and consumed by others can be documented and analysed to determine patterns of preference in relation to heritage that is of significance to the "crowd". Personalised interactions can therefore be regarded as an opportunity to change how culture is "consumed". Despite the challenges facing responsibly and ethically managed crowdsourcing culture projects, especially in how and what motivates the public to participate in this digital creation of culture, significant opportunities to better understand public engagement can also be availed by traditional museums by analysing choices the public make in creating and consuming culture on their mobile devices.

Mobile devices now allow the public to play a more proactive role in creating and accessing heritage they choose. However digital curation for crowdsourced or citizen heritage poses unique challenges to the collation and ease of access to publicly sourced heritage artefacts, be they objects, buildings or places. A key challenge to collating publicly sourced digital heritage is in addressing information management and retrieval methods for reliable, easy access to digital content ranging from images, audio and text-based information. It is generally accepted that folksonomies - the free-style tagging of information and objects (via URLs) for one's own retrieval can facilitate a more personalised access to online data. It is therefore important to investigate how folksonomies can further instigate open access for digital citizen heritage and the virtual communities that contribute to such projects.

Europeana's Pinterest experiment (2015) to allow people to share and tag heritage that is of personal significance to them is an example of how folksonomies have now morphed into collaborative virtual share spaces. Pinterest is a visual folksonomy that provides numerous access points to digital citizen heritage with particular reference to images of places, buildings and objects that are valued by the online community that creates and tags them. An impact analysis of this visual folksonomy as a self-evolving curatorial process allowing people to "pin" (tag) places and objects of interest to them and post their comments to already pinned content may reveal how often these images are consequently tagged and retrieved which may then indicate levels of engagement and reciprocity of collaboration. This future investigation of folksonomies for crowdsourced heritage may then help to determine patterns of data stewardship which can be traced in order to analyse how digital heritage is created, organised, retrieved, used and preserved. However since crowdsourced heritage facilitates everyone as a provider of data, one possible challenge is that people may be constrained by lack of or limited domain knowledge and the objectives of a heritage project. So it is proposed that contextualised 
frameworks, such as the one proposed in Fig. 4 for Afghanistan, need to be created to implement crowdsourcing initiatives that are based on an investigation of the underlying motivations and behaviour of people who will engage with crowdsourcing their culture within their unique and specific cultural, social and national milieu.

\section{Conclusions}

Despite the challenges of instigating and coordinating crowdsourcing projects for data and information creation and sharing in any domain, but in particular for cultural heritage that is under threat, an analysis of the social and political milieu can lead to strategies that successfully implement these initiatives and lead to improved outcomes. Of utmost importance and a possible key to greater success is determining and assigning appropriate change agents to engage people by promoting and being a champion of efforts for any crowdsourced project. Even though this chapter considered some of the challenges of crowdsourcing, and in this case for Afghan cultural heritage, it is hoped that one day such proposed initiatives will be more viable despite conditional circumstances. More research into motivational factors, ethical considerations and information access to crowdsourced digital culture could improve recent efforts and provide digital platforms that both current and future generations can use to connect with heritage that both informs and affirms their identities.

Open Access This chapter is distributed under the terms of the Creative Commons AttributionNoncommercial 2.5 License (http://creativecommons.org/licenses/by-nc/2.5/) which permits any noncommercial use, distribution, and reproduction in any medium, provided the original author(s) and source are credited.

The images or other third party material in this chapter are included in the work's Creative Commons license, unless indicated otherwise in the credit line; if such material is not included in the work's Creative Commons license and the respective action is not permitted by statutory regulation, users will need to obtain permission from the license holder to duplicate, adapt or reproduce the material.

\section{References}

Afghanistan. Exhibition: Hidden treasures from the National Museum, Kabul. Retrieved August 11, 2015, from http://www.nationalgeographic.com/mission/afghanistan-treasures.

Alam, S. L., \& Campbell, J. (2012). Crowdsourcing motivations in a not-for-profit GLAM context: The Australian Newspapers Digitisation Program. In 23rd Australasian Conference on Information Systems 3-5 Dec, Geelong.

APAA. Association for the Protection of Afghan Archaeology. Retrieved May 7, 2013, from http:// www.apaa.info/

Ashworth, G. J., Tunbridge, J. E., \& Graham, B. J. (2007). Pluralising pasts: Heritage, identity and place in multicultural societies. London: Pluto. 
Assmann, J., \& Czaplicka, J. (1995). Collective Memory and Cultural Identity. New German Critique, 65, 125-133.

Belk, R. W. (1990). The role of possessions in constructing and maintaining a sense of past. Advances in Consumer Research, 17, 669-676. Retrieved from http://www.acrwebsite.org/ search/view-conference-proceedings.aspx? $\mathrm{Id}=7083$.

Blake, J. (2000). On defining the cultural heritage. International and Comparative Law Quarterly, 49, 61-85. doi:10.1017/S002058930006396X.

Benard, C. (2012). Mes Aynak ARCH-Alliance for the restoration of cultural heritage. White paper. Retrieved August 7, 2015, from http://www.archinternational.org/mes_aynak.html.

Bloch, H. (2015, September 10) Mega copper deal in Afghanistan fuels rush to save ancient treasures. National Geographic. Retrieved from http://ngm.nationalgeographic.com/2015/09/ mes-aynak/bloch-text.

Brodie, N., Doole, J., \& Renfrew, C. (2001). Trade in illicit antiquities: The destruction of the world's archaeological heritage. Cambridge, England: McDonald Institute for Archaeological Research.

Brodie, N., Kersel, M. M., Luke, C., \& Tubb, K. W. (Eds.). (2006). Archaeology, cultural heritage, and the antiquities trade (Cultural heritage studies). Gainesville, FL: University Press of Florida.

Caldwell, R. (2003). Models of change agency: A fourfold classification. British Journal of Management, 14, 131-142.

Campbell, P. B. (2013). The illicit antiquities trade as a transnational criminal network: Characterizing and anticipating trafficking of cultural heritage. International Journal of Cultural Property, 20, 113-153. doi:10.1017/S0940739113000015.

Chowdhury, G., \& Ruthven, I. (2015). Cultural heritage information management issues and challenges. In G. G. Chowdhury \& I. Ruthven (Eds.), Cultural heritage information access and management (iResearch series). London: Facet.

Chowdhury, G. (2015a). Management of cultural heritage information: Policies and practices. In G. G. Chowdhury \& I. Ruthven (Eds.), Cultural heritage information access and management (iResearch series, pp. 37-62). London: Facet.

Chowdhury, S. (2015b). Cultural heritage information: Users and usability. In G. G. Chowdhury \& I. Ruthven (Eds.), Cultural heritage information access and management (iResearch series, pp. 135-152). London: Facet.

D’Alba, A., Jones, G., \& Wright, R. (2015). Comparative analysis of visitors' experiences and knowledge acquisition between a 3 dimensional online and a real-world art museum tour. Journal of Educational Multimedia and Hypermedia, 24(1), 5-22.

Dijkshoorn, C. R., Oosterman, J., Aroyo, L. M., \& Houben, G. (2012). Personalization in crowddriven annotation for cultural heritage collections. In 4th International Workshop on Personalized Access to Cultural Heritage.

DoD. Retrieved May 5, 2013 from http://www.cemml.colostate.edu/cultural/09476/afgh01.html.

Dupree, N. H. (2002). Cultural heritage and national identity in Afghanistan. Third World Quarterly, 23(5), 977-989. doi:10.1080/0143659022000028549.

ESRI. (2015). Collector for ArcGIS. Retrieved from http://www.esri.com/software/arcgis/collec tor-for-arcgis.

Europeana. Pinterest. Retrieved August 10, 2015, from https://www.pinterest.com/europeana/

FAIMS. (2014). Federated Archaeological Information Management Systems eResearch Project. Retrieved August 14, 2015, from http://research.unsw.edu.au/projects/federated-archaeolog ical-information-management-systems-eresearch-project and https://www.fedarch.org/ wordpress/about/\#About.

Flanagan, M., Punjasthitkul, S., Seidman, M., Kaufman, G., \& Carini, P. (2013). Citizen archivists at play: Game design for gathering metadata for cultural heritage. Institutions Proceedings of DiGRA 2013: DeFragging Game Studies.

Flood, F. B. (2002). Between Cult and Culture: Bamiyan, Islamic Iconoclasm, and the Museum. The Art Bulletin, 84(4), 641-659. doi:10.1080/00043079.2002.10787045. 
Francioni, F. (2008). Culture, heritage, and human rights: An introduction. In F. Francioni \& M. Scheinin (Eds.), Cultural human rights. Leiden: Martinus Nijhoff.

Garau, C., \& Ilardi, E. (2014). The 'non-places' meet the 'places': Virtual tours on smartphones for the enhancement of cultural heritage. Journal of Urban Technology, 21(1), 77-89. Retrieved from http://dx.doi.org/10.1080/10630732.2014.884384.

Gregory, J. (2014). Connecting with the past through social media: The 'Beautiful buildings and cool places Perth has lost' Facebook group. International Journal of Heritage Studies, 21, 22-45. http://dx.doi.org/10.1080/13527258.2014.884015.

Gruen, A., Remondino, F., \& Zhang, L. (2014). 3D Modeling and visualization of large cultural heritage sites at very high resolution: The Bamiyan valley and its standing Buddhas. IAPRS, 35 (B5), 522-528.

Hague Convention of 1899. The convention with respect to the laws and customs of war on land. Retrieved from www.icrc.org/ihl.nsf/INTRO150?OpenDocument

Iacovino, L. (2015). Shaping and reshaping cultural identity and memory: Maximising human rights through a participatory archive. Archives and Manuscripts., 43(1), 29-41. http://dx.doi. org/10.1080/01576895.2014.961491.

ITN-DCH. (2014). Retrieved from http://www.itn-dch.eu/index.php/about-us/

Han, K., Shih, P. C., Rosson, M. B., \& Carroll, J. M. (2014a). Understanding local community attachment, engagement and social support networks mediated by mobile technology. Interacting with Computers 2014a.

Han, K., Shih, P. C., Rosson, M. B., \& Carroll, J. M. (2014b). Enhancing community awareness of and participation in local heritage with a mobile application. CSCW 2014-Mobile Apps for Enhancing Connectedness. pp. 1144-1155.

Loh, L. (2010). Conserving for change. Journal of Architectural Education, 63(2), 71-73.

Massoudi, O. K. Afghanistan: Hidden treasures from the national museum, Kabul. Retrieved August 11, 2015, from http://museumvictoria.com.au/melbournemuseum/discoverycentre/ videos/afghanistan/

McIntosh, A. J., \& Prentice, R. C. (1999). Affirming authenticity consuming cultural heritage. Annals of Tourism Research, 26(3), 589-612.

Melbourne Museum. (2015). Retrieved August 10, from https://web.archive.org/web/ 20140112195831/http://museumvictoria.com.au/melbournemuseum/whatson/currentexhibitions/melbournestory/visitors-photo-album/ and http:/www.flickr.com/groups/ melbournemuseum

Oomen, J., \& Aroyo, L. (2011). Crowdsourcing in the cultural heritage domain: Opportunities and challenges. In $C \& T$ '11 Proceedings of the 5th International Conference on Communities and Technologies, pp. 138-149. ACM digital library http://dl.acm.org/citation.cfm?doid=2103354. 2103373

Oosterman, J., Bozzon, A. Houben, G.-J., Nottamkandath, A., Dijkshoorn, C., Aroyo, L., et al. Crowd vs. experts: Nichesourcing for knowledge intensive tasks in cultural heritage. international World Wide Web Conference Committee (IW3C2), 2014. ACM 978-1-45032744-2/14/04. http://dx.doi.org/10.1145/2567948.2576960.

Owens, T. (2013). Digital cultural heritage and the crowd curator. The Museum Journal, 56(1), 121-130.

Panoramio. Retrieved May 11, 2013, from http://www.panoramio.com/map/\#lt=34.831844\& $\ln =67.822019 \& \mathrm{z}=3 \& \mathrm{k}=2 \& \mathrm{a}=1 \& \mathrm{tab}=1 \& \mathrm{pl}=$ all

Paraschakis, D., \& Friberger, M. G. (2014, May 27-31). Playful crowdsourcing of archival metadata through social networks. ASE big data/social com/cybersecurity Conference, Stanford University. ASE@360 Open Scientific Digital Library http://www.ase360.org/han dle/123456789/45

Pearce, R. (2013, April 9). UNSW researchers push open source, Android for archaeology: FAIMS project prepares for public beta of Android-based digital tools for archaeologists. Computerworld. Retrieved from http://www.computerworld.com.au/article/458425/unsw_ researchers_push_open_source_android_archaeology/?pp $=2$

Project Mosul. (2015). http://projectmosul.org/ and http://projectmosul.org/gallery. 
Ridge, M. (2013). From tagging to theorizing: Deepening engagement with cultural heritage through crowdsourcing. The Museum Journal, 56(4), 435-450.

Risen, J. (2010, June 13). U.S. identifies vast mineral riches in Afghanistan. New York Times. Retrieved from http://www.nytimes.com/2010/06/14/world/asia/14minerals.html?_r=0

Sarianidi. (2015). http://video.nationalgeographic.com.au/video/treasure-wars/bactrian-gold-tw.

Silberman, N., \& Purser, M. (2012). Collective memory as affirmation: People-centred cultural heritage in a digital age. In E. Giaccardi (Ed.), Heritage and social media: Understanding heritage in a participatory culture (pp. 13-39). London: Routledge.

Silverman, H., \& Ruggles, D. F. (Eds.). (2007). Cultural heritage and human rights. New York: Springer.

Tait, E., MacLeod, M., Beel, D., Wallace, C., Mellish, C., \& Taylor, S. (2013). Linking to the past: An analysis of community digital heritage initiatives. Aslib Proceedings: New Information Perspectives, 65(6), 564-580. doi:10.1108/AP-05-2013-0039.

Terras, M., \& Ruthven, I. (2015). Cultural heritage information: Artefacts and technologies and digitization technologies. In G. G. Chowdhury \& I. Ruthven (Eds.), Cultural heritage information access and management (iResearch series, pp. 63-88). London: Facet.

UNESCO. (1954, May 14). Convention for the protection of cultural property in the event of armed conflict with regulations for the execution of the convention 1954. First Protocol, The Hague.

UNESCO. (1999, March 26). Convention for the protection of cultural property in the event of armed conflict with regulations for the execution of the convention 1954. Second Protocol, The Hague.

Webb, J. (2015, May 19). “Cyber-archaeology” salvages lost Iraqi art. BBC News. http://www.bbc. com/news/science-environment-32742622

Wilson, L. (2010, June 16). \$1 Trillion Motherlode of lithium and gold discovered in Afghanistan. Financial Article Summaries Today. Retrieved August 14, 2015, from http://www.mining. com/1-trillion-motherlode-of-lithium-and-gold-discovered-in-afghanistan/ 